\title{
WISATA EDUKASI IKAN SEBAGAI TEMPAT RUANG KETIGA
}

\author{
Winanta ${ }^{1)}$, Budi Adelar Sukada ${ }^{2)}$ \\ ${ }^{1)}$ Program Studi S1 Arsitektur, Fakultas Teknik, Universitas Tarumanagara, winanta23@gmail.com \\ ${ }^{2)}$ Program Studi S1 Arsitektur, Fakultas Teknik, Universitas Tarumanagara, budisukada@yahoo.com
}

Masuk: 13-07-2020, revisi: 31-07-2020, diterima untuk diterbitkan: 24-09-2020

\begin{abstract}
Abstrak
Kehidupan pada daerah Jakarta utara penuh dengan aktivitas dan rutinitas keseharian dengan laut; karena sebagian besar masyarakat disana bekerja sebagai nelayan dan juga menjual hasil tangkapan dari laut. Jenis aktifitas wisata yang dapat dilakukan di Jakarta, lebih tepatnya di Jakarta utara yaitu wisata perairan antara lain yaitu renang, pemancingan, dayung perahu, olahraga air, dan perikanan wisata. Perikanan wisata adalah suatu pemanfaatan usaha perikanan sebagai obyek kunjungan wisata. Kegiatan perikanan wisata dapat berupa penangkapan ikan sebagai hobi (game fishing), pemancingan ikan sebagai hobi (sport fishing), berkunjung ke lokasi budidaya ikan hias yang dilengkapi dengan objek wisata berupa "display" ikan hias (ornamental fish). Tujuan proyek ini untuk mengedukasi masyarakat mengenai ikan dan meningkatkan kualitas sosial masyarakat. Program utama yang ditawarkan pada proyek ini terdapat area display akuarium sebagai edukasi ikan, dan juga penangkaran ikan untuk memberi perkembangbiakkan mengenai ikan, terdapat ruang santap terbuka untuk ruang makan yang disertai suasana ikan, serta dapat juga memancing ikan, dan area penunjang yaitu ruang auditorium sebagai edukasi dan juga tempat sosial bagi masyarakat untuk mengadakan acara maupun aktivitas sosial.
\end{abstract}

Kata Kunci: arsitektur; edukasi; ikan; sosial; wisata

\begin{abstract}
Life in the North Jakarta area is full of activities and daily routines with the sea, because most of the people there work as fishermen and also sell their catch from the sea. Types of tourism activities that can be carried out in Jakarta, more precisely in North Jakarta, are water tourism, including swimming, fishing, rowing boats, water sports, and fishing tourism. Tourism fisheries are utilization of fishery business as an object of tourist visit. Tourism fishing activities can be in the form of fishing as a hobby (game fishing), fishing as a hobby (sport fishing), visit to an ornamental fish culture location that is equipped with an attraction in the form of "display" (ornamental fish). The aim of this project is to educate the public about fish and improve the social quality of the community. The main program offered in this project is the aquarium display area for fish education, and also fish breeding to provide reproduction about fish, there is an open dining room accompanied by the atmosphere of the fish, and can also fish fishing, and other supporting areas, is the auditorium as education and also a social place for the community to hold events and social activities.
\end{abstract}

Keywords: architecture; education; fish; social; tourism

\section{PENDAHULUAN}

\section{Latar Belakang}

Istilah 'ruang ketiga' (third place) semakin sering diperbincangkan dalam konteks pembangunan perkotaan. Secara konseptual, Ray Oldenburg mendefinisikan ruang ketiga sebagai ruang yang berada di antara rumah (ruang pertama) dan tempat bekerja/ belajar/ berkegiatan sehari-hari (ruang ke dua) sebagai titik bertemu dan berinteraksinya masyarakat. Ruang ketiga memang sangat strategis menjadi "panggung pertunjukan" karena lokasinya yang selalu ramai orang. la dapat digunakan untuk menampilkan aneka ekspresi budaya. 


\section{Rumusan Permasalahan}

Berdasarkan latar belakang diatas dapat diketahui terdapat masalah yang terjadi:

a. Pentingnya Third Place untuk masyarakat Jakarta dalam menghadapi kesibukan dan aktivitas yang dialami setiap hari sebagai nelayan, sebagai sarana untuk rekreasi dan interaksi terutama bagi masyarakat yang bekerja disekitarnya.

b. Bagaimanakah reaksi masyarakat terkait pembangunan third place zaman sekarang?

c. Bagaimanakah program arsitektur yang mampu membangun tempat yang menarik secara positif?

d. Bagaimanakah timbal balik program arsitektur tersebut terhadap kota dan masyarakat?

\section{Tujuan}

Tujuan perancangan proyek ini menjadi suatu tujuan yang umum dan khusus, yaitu:

a. Tujuan Umum:

Menciptakan proyek yang terbuka sebagai wujud interaksi social dengan program arsitektur yang interaktif dan positif dalam mewadahi masyarakat dan lingkungan sekitar.

b. Tujuan Khusus:

Menciptakan wadah dan fasilitas untuk wujud menghubungkan antar masyarakat untuk saling berbagi pengetahuan serta pengalaman, baik dalam komunitas antar individual masyarakat serta menyediakan fasilitas yang mendukung untuk edukasi ikan dalam meningkatkan pengetahuan ikan yang luas. Memberikan pengalaman ruang yang berbeda untuk mengedukasikan ikan dan juga perkembang biakan nya.

\section{KAJIAN LITERATUR}

\section{Open Architecture for The Third Place}

Menurut (Hertzberger,2016), open architecture adalah desain yang berkaitan dengan empati, fakta bahwa Anda menempatkan diri perancang di tempat orang-orang yang menggunakannya. Menurutnya, terlalu banyak arsitek sibuk dengan struktur bangunan tetapi tidak dengan manusianya. Jadi sebagian besar waktu arsitek tidak berpikir tentang bagaimana perasaan orang di gedung mereka. Dalam buku panduan STUPA 8.29 bahwa "Open Architecture for The Third Place". Open Architecture sebagai Third Place dapat diartikan dengan melihat hal-hal yang terkait dengan konteks kebutuhan masyarakat kota dan modernisasi teknologi, informasi dan individu. Dalam Open Architecture for The Third Place, konflik public private menjadi hal unik yang berpotensi untuk dikembangkan (bukan dihilangkan). Contoh lain yaitu paradigma openness, closness, dan voidness. Openess adalah program yang terbuka terhadap apapun (aktivitas, fungsi, pengguna, dII), sedangkan closeness program yang tertutup, diantara itu adalah voidness.

\section{Third Place}

Tempat ketiga adalah lingkungan sosial yang terpisah dari dua lingkungan sosial rumah ("tempat pertama") dan tempat kerja ("tempat kedua"). Contoh tempat ketiga adalah lingkungan seperti gereja, kafe, klub, perpustakaan umum, atau taman. Dalam bukunya yang berpengaruh, The Great Good Place, Ray Oldenburg $(1989,1991)$ mengemukakan bahwa tempat ketiga penting bagi masyarakat sipil, demokrasi, keterlibatan sipil, dan membangun perasaan rasa tempat. Tempat ketiga memiliki delapan karakteristik, yaitu:

a. Netral

Pengunjung tidak terikat ke daerah finansial, politik, hukum, atau sebaliknya dan bebas untuk datang dan pergi sesuka mereka.

b. Leveling

Tempat ketiga tidak mementingkan status individu dalam suatu masyarakat. Memiliki status rasa kesamaan di antara penghuninya. 
c. Percakapan adalah kegiatan utama

Obrolan menyenangkan dan bahagia adalah fokus utama dari aktivitas di tempat ketiga, meskipun tidak harus menjadi satu-satunya aktivitas.

d. Aksesibilitas dan akomodasi

Tempat ketiga harus terbuka dan mudah diakses. Dan juga harus akomodatif, artinya dapat memenuhi kebutuhan didalamnya, dan semua penghuni merasa kebutuhan mereka telah terpenuhi.

Menurut pemaparan Suwardana Winata ST., M.Arch., mengenai Third Place; yaitu "Neighborhood Facilities" dalam hal ini fasilitas dapat melayani 1 kelurahan. Menurutnya, Third Place bersifat usual atau umum. Di dalam Third Place siapapun diperbolehkan masuk dan menikmatinya tanpa memandang tingkatan ekonomi, sosial, budaya, dll. Neighborhood Facilities bersifat publik, tidak boleh dikenakan biaya. Fungsi dari third place harus jelas dan pengunjung dapat saling berinteraksi. Menurut pemaparan Ir. Diah Anggraini, M.Si., Third Place dapat mewadahi kebutuhan sehari-hari. Third place dinilai dapat menyatukan beberapa orang untuk berinteraksi yang bermanfaat.

\section{Arsitektur dalam Konteks Open Architecture}

Menurut buku panduan STUPA 8.29, open architecture menjadi kesempatan untuk menciptakan sebuah platform arsitektur yang dapat dikombinasikan dengan berbagai macam keadaan dan kondisi masyarakat dalam hal ini masyarakat pekotaan Jakata atau kota besar lainnya. Open architecture sebagai platform akan dibuat berdasarkan salah satu dari tiga kategori, yaitu kategori commercial, hospitality, dan entertainment. Commercial yang dimaksud disini adalah kategori yang terkait dengan aktivitas jual beli baik jasa maupun barang dan aktivitas lain yang mendukung jua beli. Hospitality merupakan aktivitas yang terkait dengan penerimaan tamu, pengunjung, dan juga pelayanan terhadap masyarakat (konsumen). Entertainment terkait dengan ekspresi, karena itu erat kaitannya dengan art dan kultur, selain itu terkadang memiliki hubungan dengan edukasi. Ketiga kategori ini dibutuhkan masyarakat terutama masyarakat kota.

\section{Wisata Air}

Dalam UU No.9/1990 tentang kepariwisataan, dinyatakan bahwa pariwisata adalah segala sesuatu yang berhubungan dengan wisata, termasuk pengusahaan obyek dan daya tarik serta usaha- usaha yang terkait di bidang tersebut. Apabila dikaitkan dengan pariwisata air berarti segala sesuatu yang berhubungan dengan wisata air, termasuk pengusahaan obyek dan daya tarik wisata air, misalnya pemanfaatan pemandangan alam dan keindahan kawasan perairan karena letak geografis yang didukung dengan adanya kegiatan rekreasi dan atraksi wisata air seperti memancing, berenang, berperahu, atau olahraga air. Pariwisata air memiliki hubungan yang erat dengan unsur-unsur sebagai berikut:

a. Pariwisata air adalah kegiatan bepergian dengan tujuan atau obyek pemandangan alam maupun buatan berupa kawasan perairan.

b. Pariwisata air merupakan kegiatan yang dilakukan diluar kegiatan sehari-hari misalnya dengan menikmati pemandangan kawasan perairan.

c. Pariwisata air selalu dikaitkan dengan penggunaan fasilitas-fasilitas wisata yang tersedia yang mendukung kegiatan wisata air.

d. Pariwisata air dikaitkan dengan kegiatan bersenang-senang atau hiburan menikmati pemandangan atau melakukan kegiatan atraksi wisata air. 


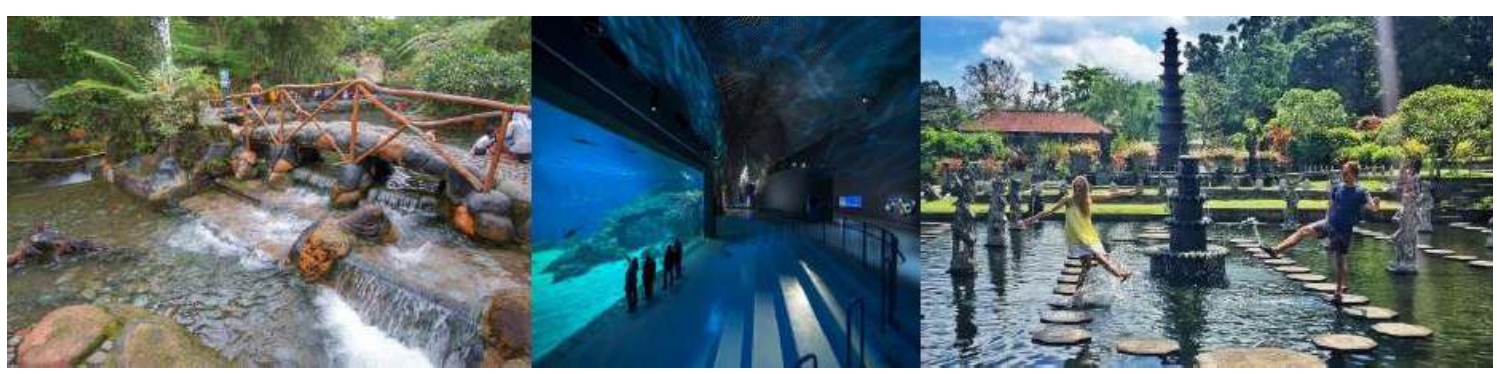

Gambar 1. Wisata Air

Sumber: Google Image

\section{Jenis Wisata Air}

Aktifitas wisata yang mungkin dapat dilakukan di perairan waduk atau danau antara lain yaitu renang, pemancingan, dayung perahu, olahraga air, dan perikanan wisata. Perikanan wisata adalah suatu pemanfaatan usaha perikanan sebagai obyek kunjungan wisata. Kegiatan perikanan wisata dapat berupa penangkapan ikan sebagai hobi (game fishing), pemancingan ikan sebagai hobi (sport fishing), kunjungan ke lokasi budidaya ikan hias/konsumsi yang dilengkapi dengan daya tarik berupa display ikan hias (ornamental fish). Untuk perairan waduk atau danau yang dalam maka wadah budidaya tersebut dapat berupa keramba jaring apung (floating net cage), sedangkan untuk perairan dangkal dapat menggunakan empang/sistem pagar (culture system).

\section{METODE}

Penelitian yang dilakukan dengan observasi kawasan Muara Angke, Kelurahan Pluit, Kecamatan Penjaringan, Kota Jakarta Utara. Pada hari Minggu, 19 Januari 2020. Kelurahan ini memiliki penduduk sebesar 105.203 jiwa dan luas $3,9543 \mathrm{~km}^{2}$ dan juga mayoritas tinggal dan berdekatan dengan pekerjaan yang tidak jauh dari nelayan.

\section{Metode Pengumpulan Data}

a. Observasi

Observasi adalah suatu kegiatan yang dilakukan dengan mengamati dan mencatat secara sistematis terhadap gejala atau fenomena yang diselidiki.

b. Wawancara

Wawancara merupakan suatu kegiatan yang dilakukan dengan cara bertanya langsung kepada pihak yang terlibat (narasumber). Wawancara ini dilakukan pada nelayan dan warga yang tinggal dan bekerja setiap harinya.

c. Dokumentasi

Dokumentasi merupakan metode yang digunakan untuk mencari data yang diperlukan berdasarkan peristiwa yang ada. Dokumentasi ini dilakukan dengan cara mendokumentasikan tapak perancangan. 


\section{DISKUSI DAN HASIL}

\section{Studi Kawasan}

Berikut temuan terkait observasi lapangan yang dirangkum oleh penulis

Tabel 1. Hasil Temuan Kondisi Lapangan

\begin{tabular}{lll}
\hline NO & Foto Lapangan & \begin{tabular}{l} 
Identifikasi Kondisi Lapangan \\
\hline 1
\end{tabular} \\
\hline 2 & $\begin{array}{l}\text { Terdapat banyak } \\
\text { pemukiman yang mayoritas } \\
\text { bekerja sebagai nelayan } \\
\text { dan pegawai pasar ikan }\end{array}$ & $\begin{array}{l}\text { Pada sekitar tapak terdapat } \\
\text { Kantor Dinas Perhubungan } \\
\text { PT. Transjakarta serta } \\
\text { terdapat pelabuhan. }\end{array}$ \\
\end{tabular}

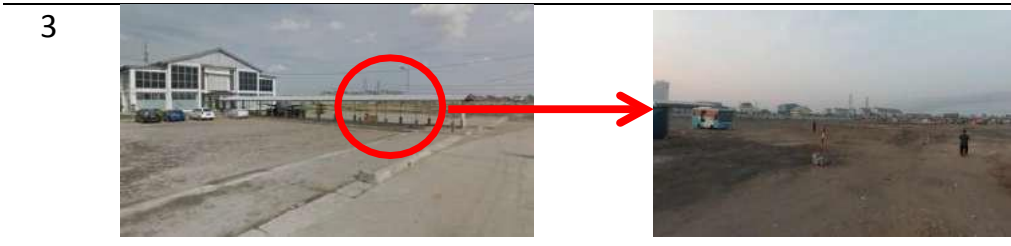

4
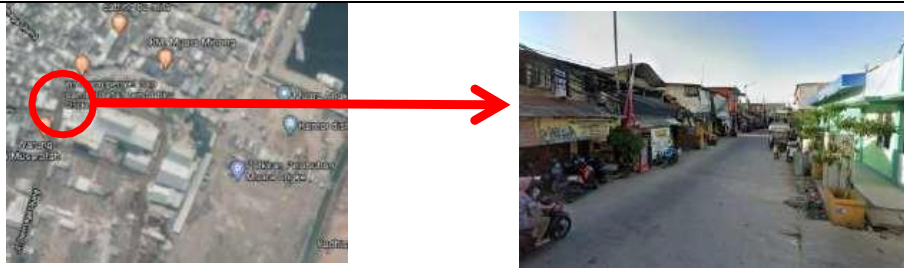
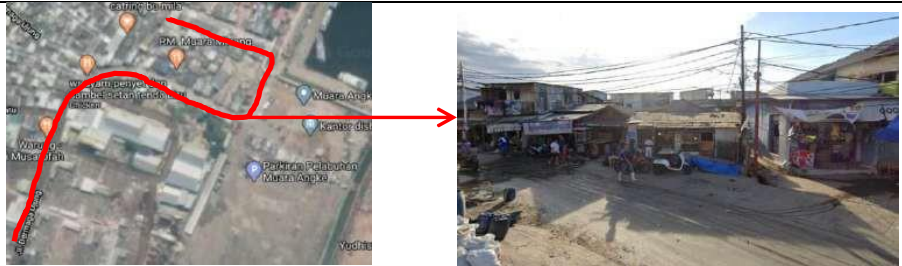

Dipinggir jalan raya dekat area tapak terpilih terdapat pemukiman penduduk yang yang mayoritas bekerja sebagai nelayan serta sebagai buruh pabrik.

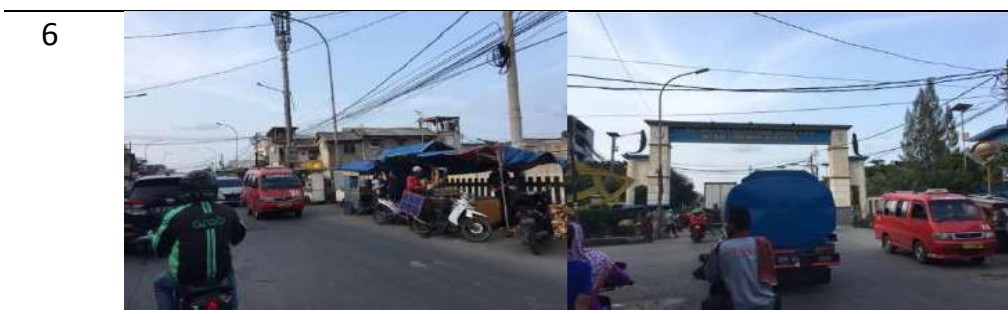

Jl. Dermaga Ujung sebagai salah satu akses utama menuju tapak dilalui oleh terdapat angkutan umum angkutan umum (angkot Jaklingko U11) dengan rute menuju Muara Baru dan Muara Angke. 


\section{Profil Tapak}

Tabel 2. Profil Tapak

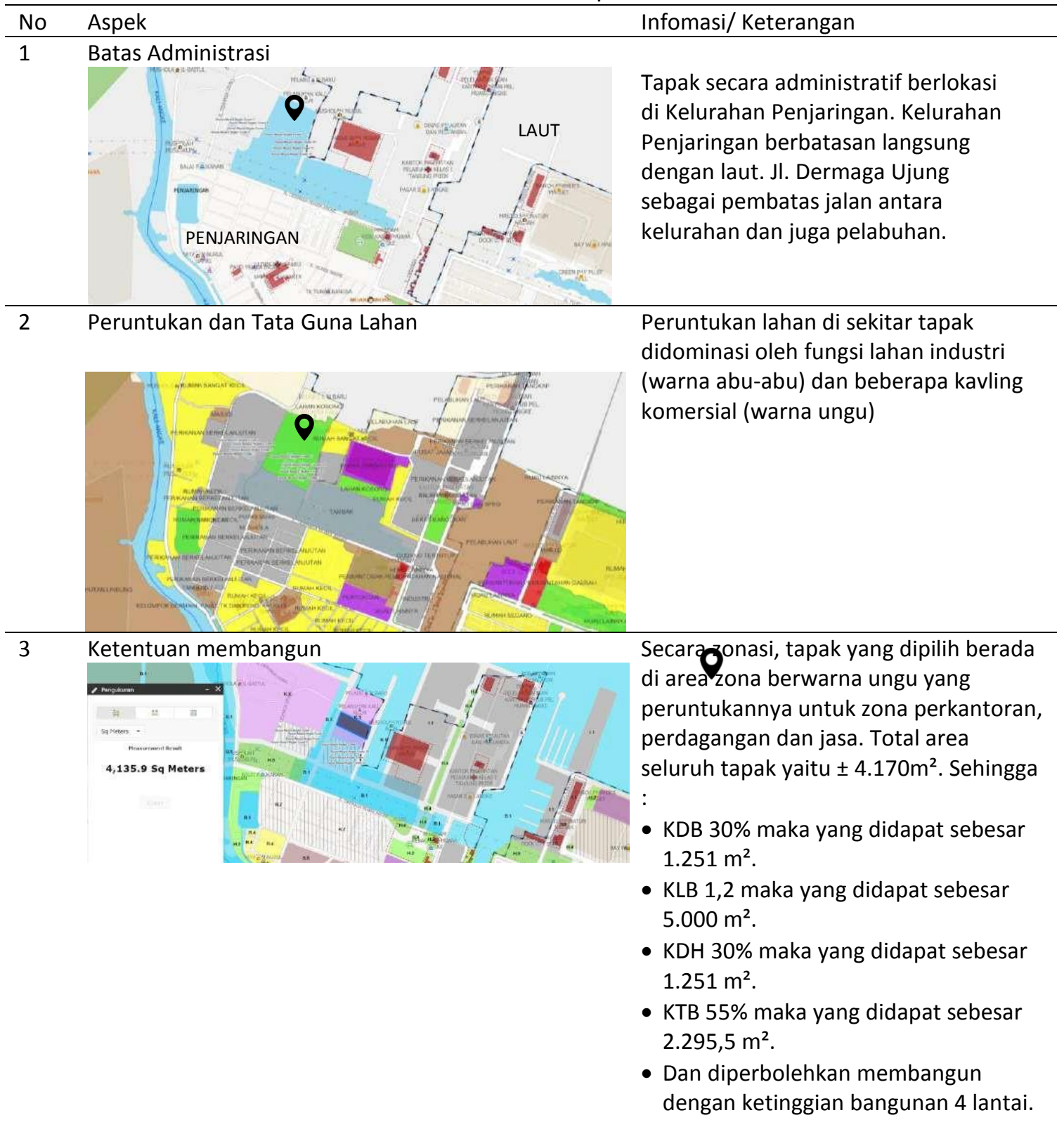

Sumber: Jakartasatu.go.id

\section{Analisis Kawasan}

Akses menuju tapak dapat dilalui dengan jalan kolektor primer yang dapat ditempuh dengan angkutan umum B-11, transjakarta dan juga gojek, kemudian dapat berjalan kaki sejauh $\pm 10 \mathrm{~m}$. akses menuju tapak dapat ditempuh dengan mudah dengan transpoertasi umum yang ada, dan dapat ditempuh dengan kendaraan pribadi. 


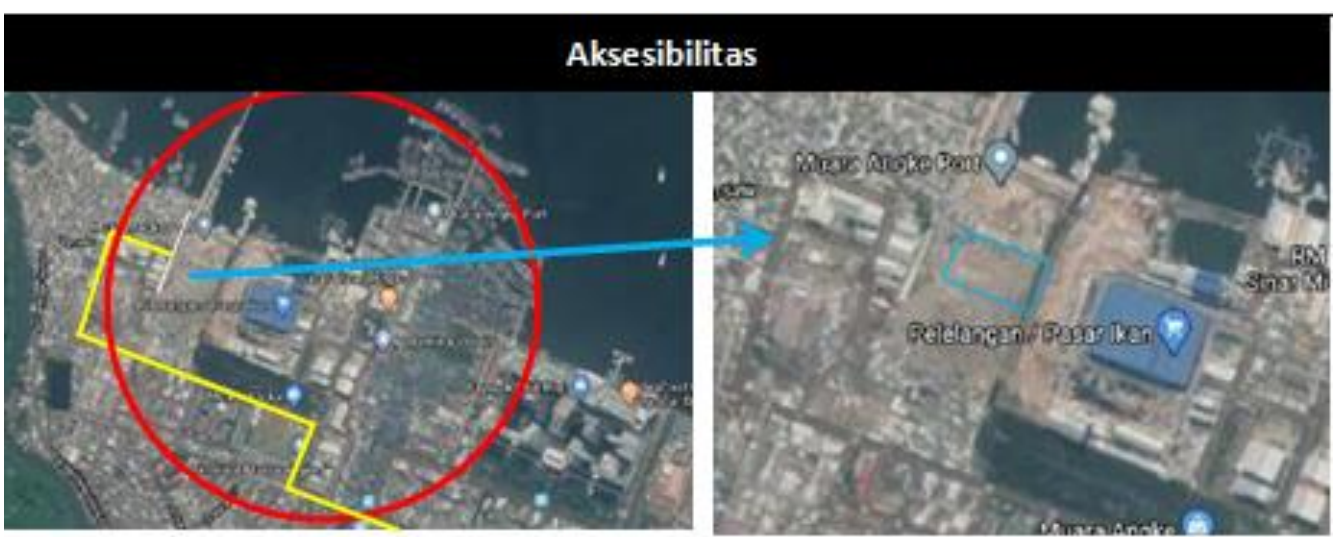

JI. Dermaga - Jalan kolektor Primer dan jalur angkutan umum dengan 2 Il Dermaga Ujung - Jalan di pelabuban dengan 1 jalur.

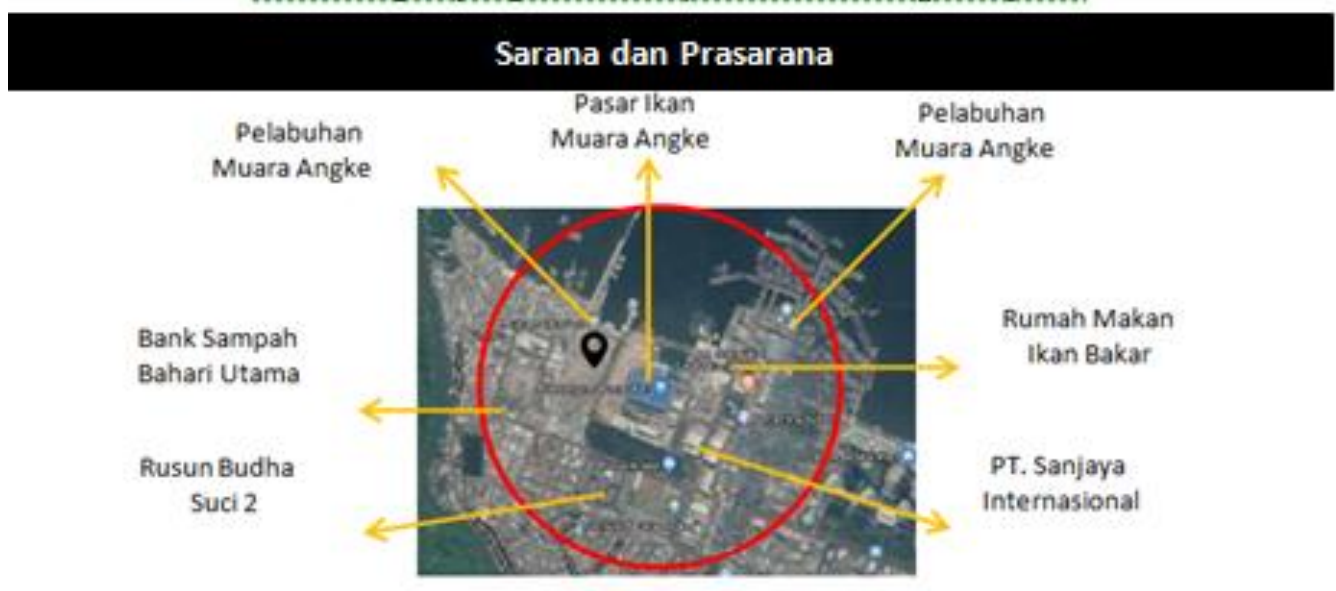

\section{Solid \& Void}

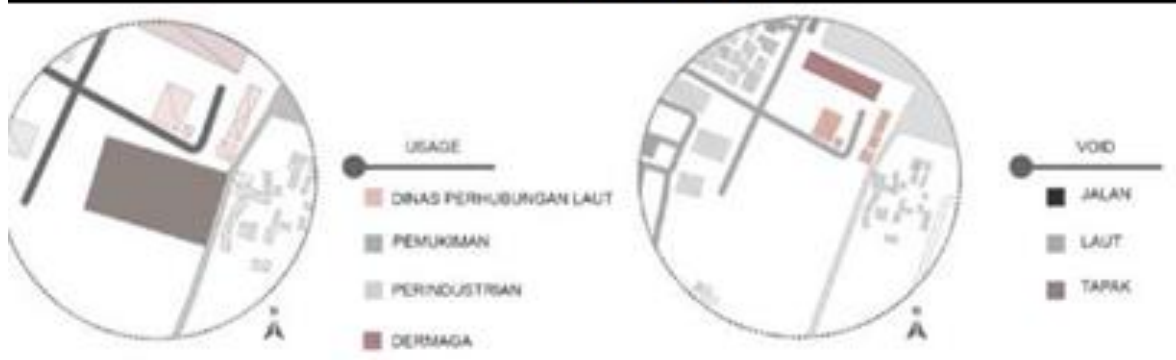

Analisis SWOT

\begin{tabular}{|c|c|c|}
\hline$S$ & $W$ & \\
\hline $\begin{array}{l}\text { - DEKAT DENGAN LAUT } \\
\text { - DILALUI ANGKUTAN UMUM } \\
\text { - TANAH VANG MASIH LUAS } \\
\text { - DILEWATI JALUR PELABUHAN } \\
\text { - DIKELIIUNGI KAWASAN PABRIK } \\
\text { DAN PEMUKIMAN }\end{array}$ & $\begin{array}{l}\text { - DILEWATI JALUR PERINOUSTAUN } \\
\text { - DILEWATI BEBERAPA TRUK } \\
\text { - KURANG NYA PEDESTRIAN } \\
\text { - IARAK YANO JAUH DARI JALUR } \\
\text { UTAMA }\end{array}$ & MUARAANGKE \\
\hline$T$ & 0 & \\
\hline $\begin{array}{l}\text { - TERDAPAT PEDAGANG KAUKI LIMA } \\
\text { - TAPAK BERADA DI DEKAT UJUNO } \\
\text { DERMAGA }\end{array}$ & $\begin{array}{l}\text { - DIBERIKAN AKSES YANG } \\
\text { MEMPERMUOAH MENUUU TAPAK } \\
\text { - SEBAGAI TEMPAT WISATA PENDUDUK } \\
\text { MAUPUN PENDATANG } \\
\text { - MENUMIEAH DAYA TARIKICIRI KHAS }\end{array}$ & $\overline{=}$ \\
\hline
\end{tabular}

Gambar 2. Analisis Kawasan

Sumber: Penulis, 2020 


\section{Analisis Tapak}

Tapak berokasi di Jl. Dermaga Muara Ujung Penjaringan No.1, Pelelangan Ikan, Muara Angke, Kelurahan Pluit, Kecamatan Penjaringan, Kota Jakarta Utara, Provinsi DKI Jakarta. Analisis tapak meliputi berbagai aspek seperti faktor angin, matahari, sirkulasi, kebisingan dan view.

a. Akses

Lokasi tapak terletak pada layer kedua. Jl. Muara Baru dilewati oleh Angkot U11 berwarna merah. Untuk mencapai tapak, dengan berjalan kaki dan lokasi tidak jauh dari layer 1. Jalan tersebut juga dilalui oleh minitrans bus Transjakarta.

b. Angin

Angin dapat masuk ke tapak karena pengaruh angin dari laut dan udara yang baik dari laut.

c. Matahari

Matahari yang berasal dari timur ke barat dapat di tapak karena tidak ada bangunan yang tinggi.

d. Sirkulasi

Sirkulasi yang mudah ke tapak karena tidak ada jalan kecil dan juga langsung dengan Jl. Dermaga Ujung dengan pelabuhan kapal.

e. Kebisingan

Kebisingan terjadi karena adanya aktivitas dari laut karena terdapat pelabuhan kapal, dan tingkat kebisingan lain nya kurang karena terdapat rumah penduduk.

f. View

View ke tapak dapat terlihat karena masih banyak tanah kosong, dan untuk view dr tapak ke sekitar dapat lebih menarik ke arah utara karena langsung melihat keindahan laut dan juga terdapat kapal berlabuh.

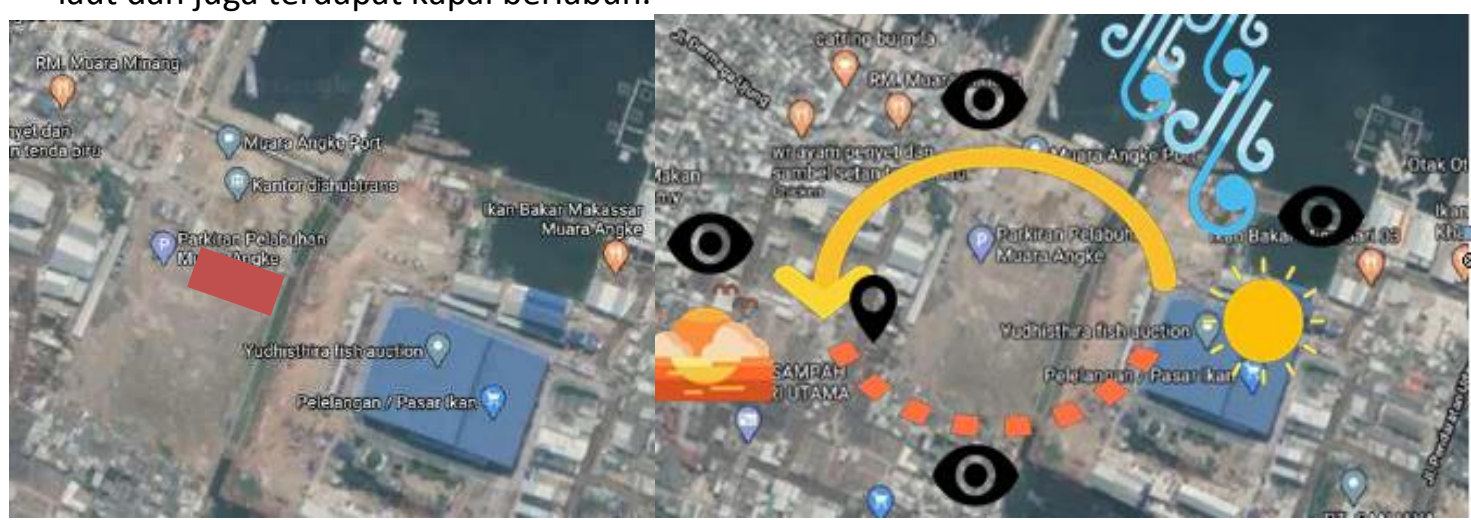

Gambar 3. Ilustrasi Analisis Tapak

Sumber: Penulis, 2020

\section{Rencana Program dan Aktivitas}

Dari hasil wawancara dan analisa serta survey lapangan, third place yang mereka butuhkan berupa kebutuhan mereka yang mencakup semua, seperti tempat untuk saling berinteraksi, warga sekitar membutuhkan Tempat Pembudidayaan Ikan Kecil agar ikan dapat dikelola dengan baik dan berkembang biak dan tumbuh sehingga dapat dijadikan wisata edukasi. Hal tersebut akan diwujudkan adalah tempat wisata edukasi ikan yang di dalamnya diisi oleh jenis - jenis ikan serta juga penangkaran yang akan di kelola oleh orang yang ahli agar tetap baik dan berkembang biak dan memiliki kualitas yang bagus serta memiliki cagar wisata yang tinggi. Pembudidayaan ini bukan hanya untuk ikan namun menyediakan fasilitas untuk berinteraksi antar orang dengan adanya aquarium dan sistem penanaman pohon (akuaponik) yang ramah bagi semua kalangan dan berbagai usia. 


\section{Konsep Desain}

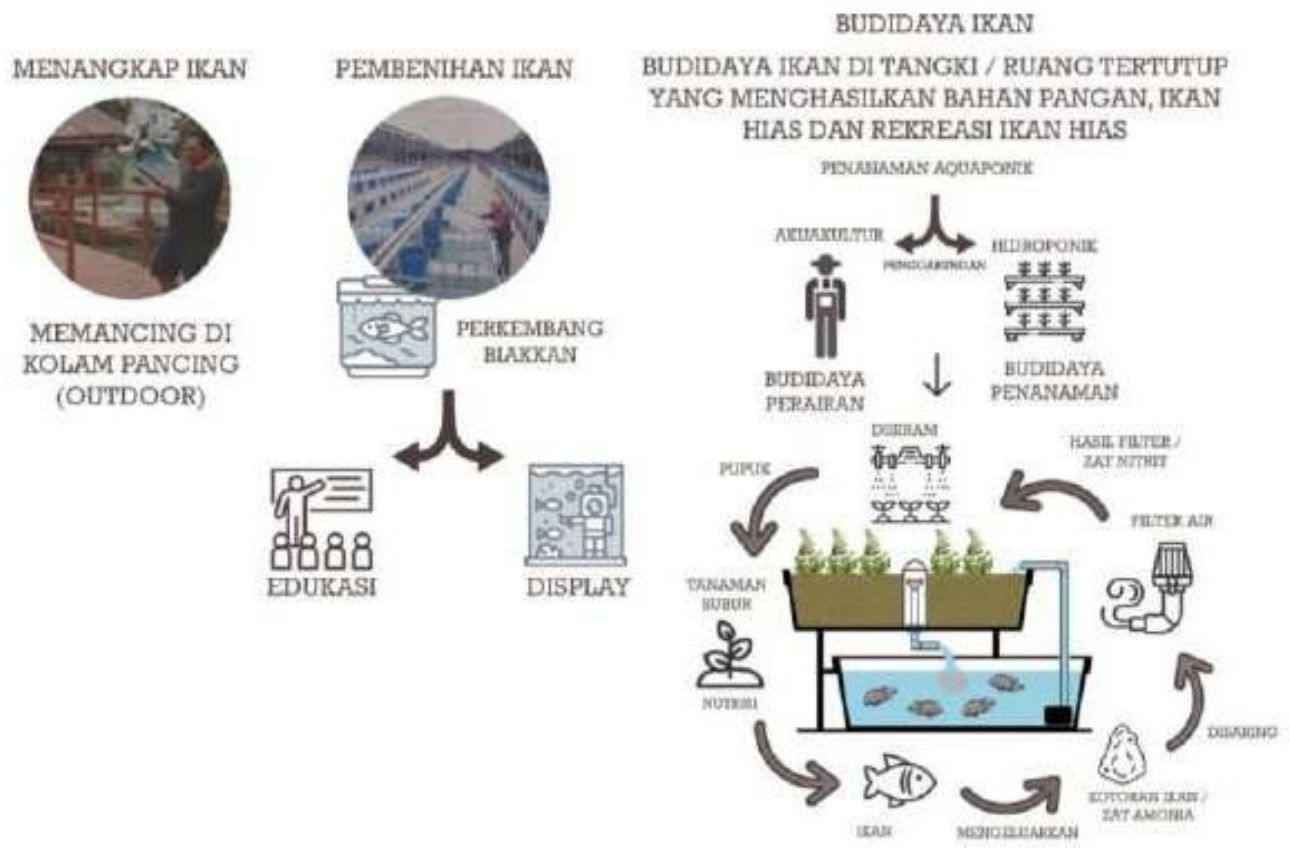

Gambar 4. Infografis Konsep Perancangan

Sumber: Penulis, 2020

\section{Bangunan Utama}

Bangunan utama pada bangunan ini berfungsi sebagai tempat dimana mereka dapat menikmati berbagai jenis ikan dan juga sebagai edukasi, dengan adanya display aquarium dan juga penangkaran ikan (warna kuning), sehingga dapat dipelajari bagaimana proses penangkaran ikan yang baik dan benar sesuai dengan ahli/pakar nya. Dan pada bagian belakang dilengkapi dengan adanya ruang santap yang berguna untuk ruang santai dan makan dinikmati dengan suasana penangkaran ikan (warna abu-abu). Bagian depan sebagai parkir.

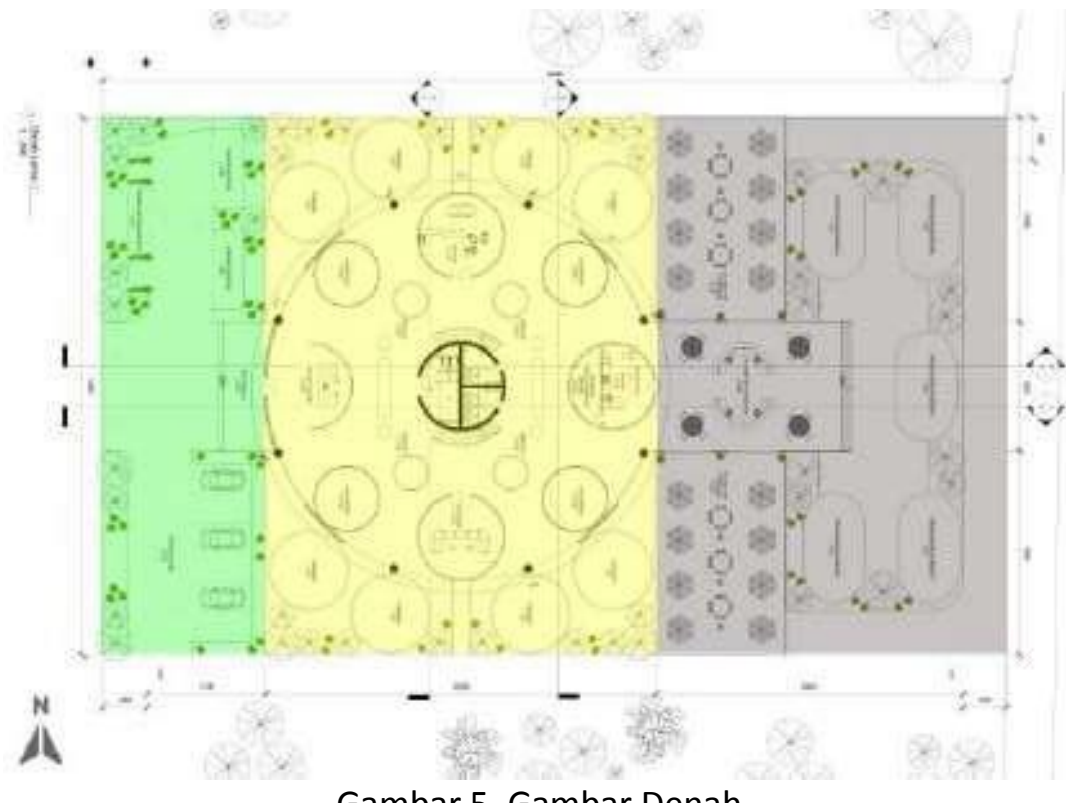

Gambar 5. Gambar Denah

Sumber: Penulis, 2020 
Desain pada bangunan ini menunjukkan dimana bangunan ini terbuka dan terekspos, sehingga dengan tampilan unik nya dapat terlihat sisi aquarium sebagai edukasi. Hal ini bertujuan agar mendapatkan view serta udara yang sangat baik, sehingga dibuat bulat agar dari berbagai sisi dapat dilihat dari dalam maupun luar. Bangunan diupayakan mendapatkan view serta udara yang sangat baik, sehingga dibuat bulat agar dari berbagai sisi dapat dilihat dari dalam maupun luar. Bentuk menyerupai gelembung karena dengan konsep gelembung agar bangunan mendapatkan udara secara alami karena mendapatkan angin dari laut.

Dapat terlihat dari potongan diatas dengan desain konsep dengan adanya bentang lebar dengan sistem core ditengah, serta memiliki utilitas yang berada di tengah untuk utilitas yang seimbang setiap lantai. Akses menuju tiap lantai terdapat ditengah dengan adanya tangga serta jarak yang sesuai tiap lantai agar aman dan juga sesuai dengan sistem kebakaran. Dengan jarak tinggi setiap lantai $4 \mathrm{M}$. Dari sisi depan bangunan pada bagian kiri terdapat lapangan parkir dibuat untuk memenuhi pengunjung. Dengan adanya parkir kendaraan bermotor serta mobil, dan disediakan lapangan parkir sepeda juga.

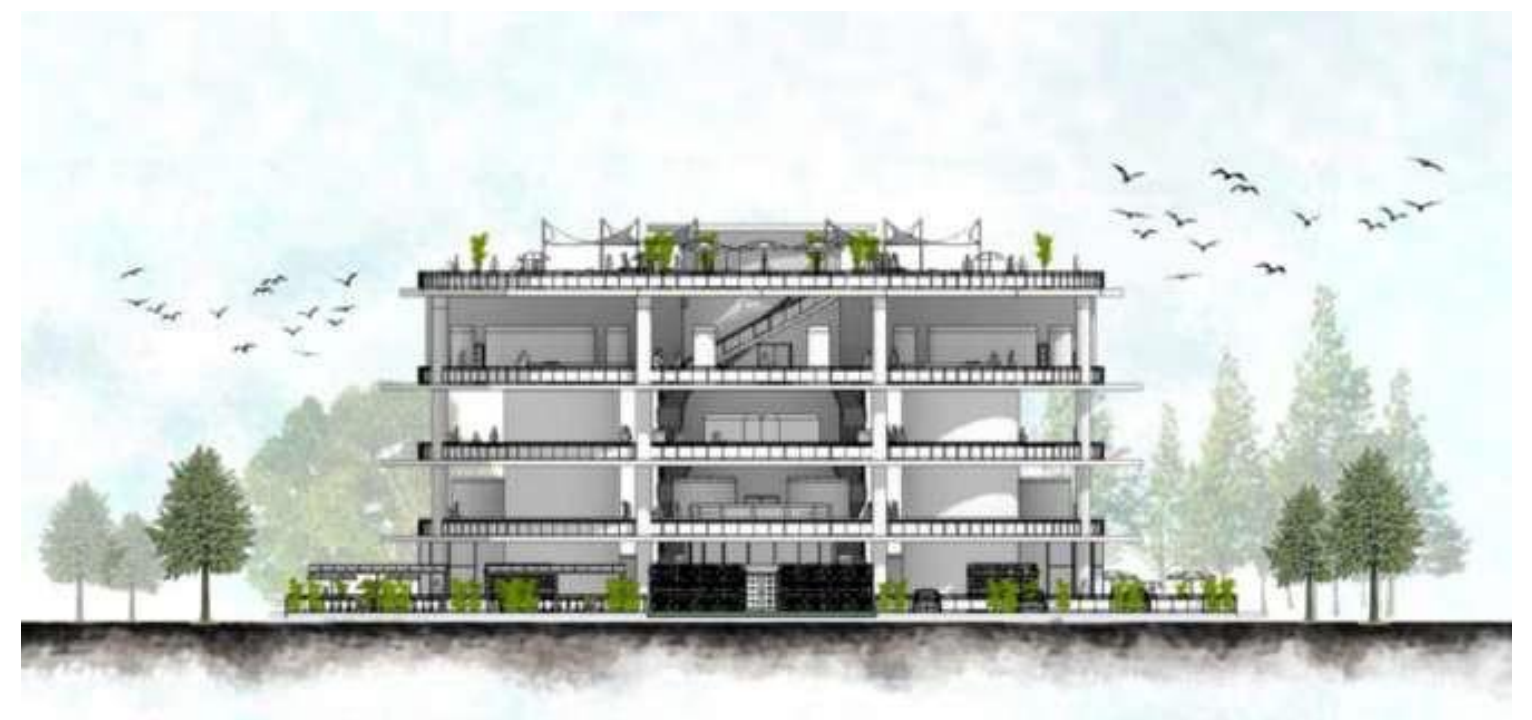

Gambar 6. Gambar Tampak

Sumber: Penulis, 2020

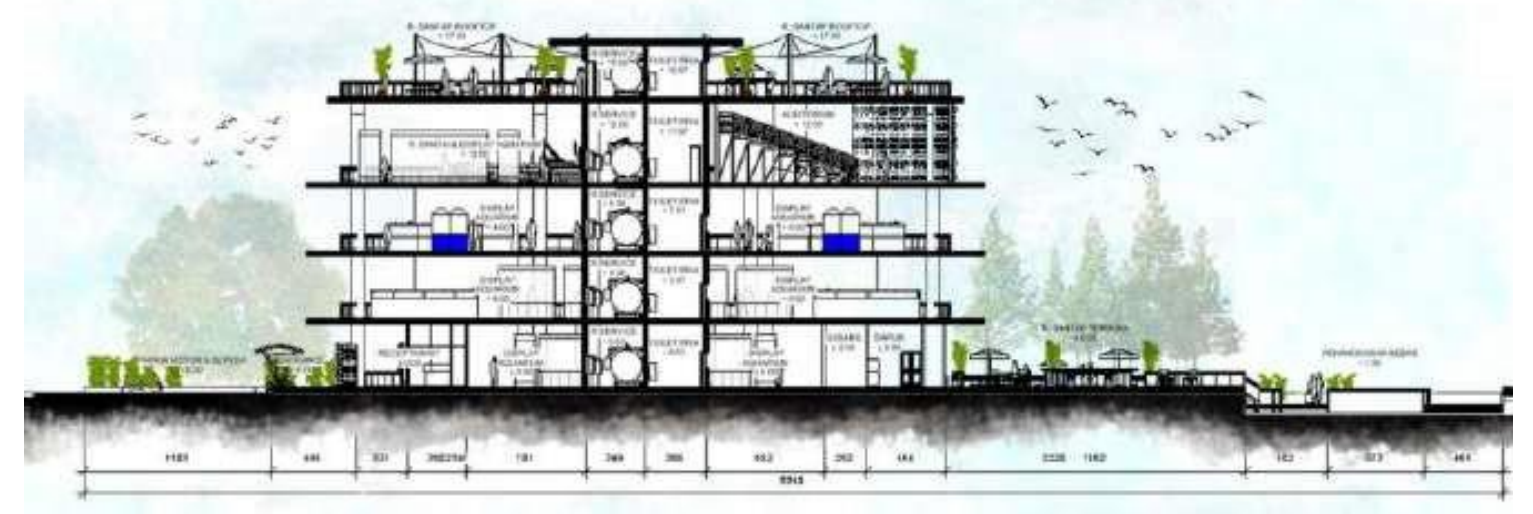

Gambar 7. Gambar Potongan

Sumber: Penulis, 2020 


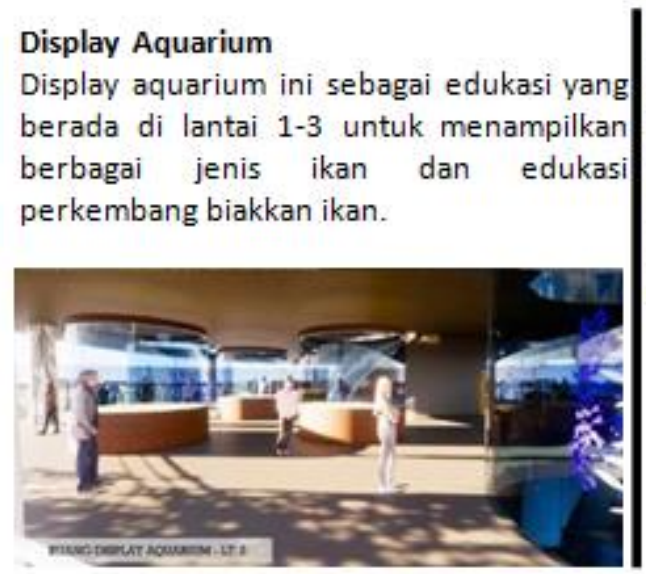

Display Aquarium

Display aquarium in berbaga di lantai 1-3 untuk menampilkan perkembang biakkan ikan.

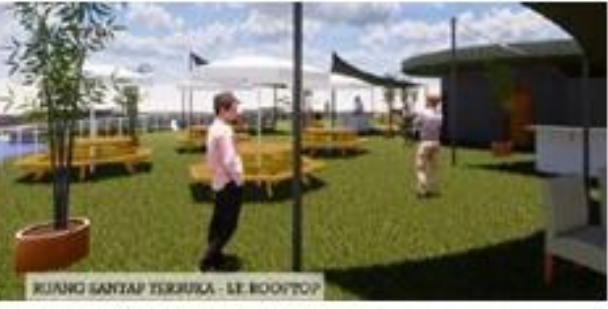

\section{Ruang Santap Terbuka}

Desain pada ruang santap ini terbuka sehingga dapat menikmati hidangan makanan disertai dengan view yang terbuka dan juga udara yang terbuka secara alami

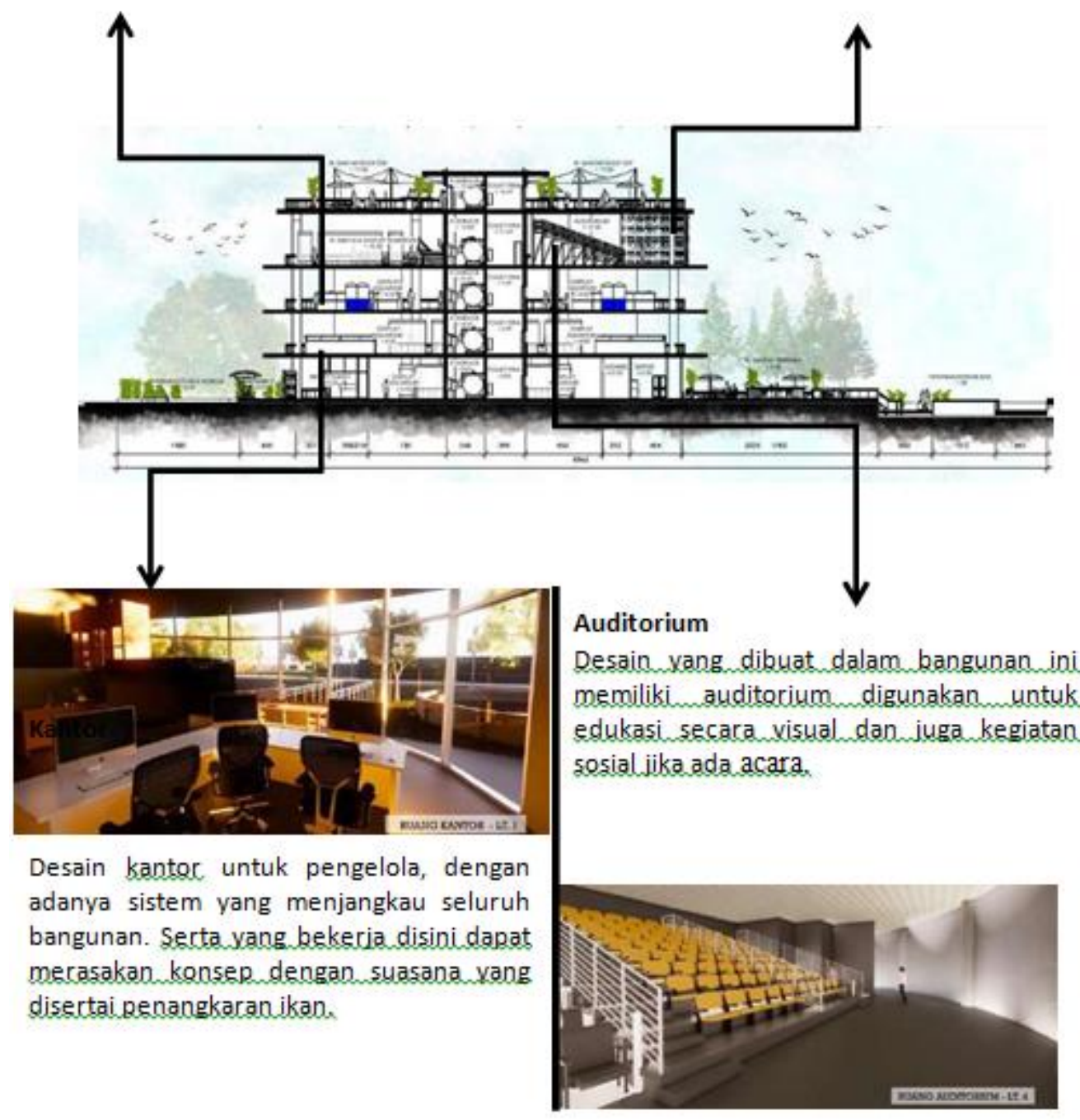

Gambar 8. Beberapa Fasilitas Penunjang di Dalam Bangunan Sumber: Penulis, 2020

\section{KESIMPULAN DAN SARAN}

Kelurahan Penjaringan terkenal dengan kreativitasnya dengan adanya mural dibeberapa titik. Dari hasil wawancara juga dikatakan bahwa yang bekerja di dalam Pasar Ikan Muara Angke bertempat tinggal di sekitar muara angke. Ada juga yang bertempat tinggal diluar Muara Angke, seperti di Tangerang dan Cilincing. Dan mereka bekerja sebagai pedagang aneka macam ikan dan binatang laut di dalam Pasar Ikan Muara Angke. Dari first place dan 
second place maka warga sekitar membutuhkan Tempat Wisata Edukasi Air agar ikan dapat dikelola dengan baik dan berkembang biak dan tumbuh serta menjadikan tempat yang bermanfaat sebagai edukasi dari berbagai jenis ikan di laut serta dapat di jadikan tempat publik yang disertai dengan suasana air untuk menambah suatu perasaan yang berada di laut.

\section{REFERENSI}

3LHD. (2016, November 21). Karlovac Freshwater Aquarium and River Museum. Retrieved Juli 12, 2020, from Arch Daily: https://www.archdaily.com/799671/karlovacfreshwater-aquarium- and-river-museum3lhd?ad_source=search\&ad_medium=search_result_all

Academia. (2006). Metode Penelitian Kuantitatif \& Kualitatif. Retrieved Januari 2020, from Graha Ilmu: https://www.academia.edu/22424178/Buku_Metodologi_Penelitian_Kuantitatif_d

Adiutama, G. (2019, November 9). Melestarikan Warisan Budaya di Ruang Ketiga. Retrieved Februari 2020, from Ketempatan Kontekstual Membaca Ruang: https://ketempatan.com/blog/melestarikan-warisan-budaya-di-ruang-ketiga/

Architects, B. K. (2014, Februari 17). Antalya Aquarium. Retrieved Januari 2020, from Arch Daily: https://www.archdaily.com/477163/antalya-aquarium-bahadir-kularchitects?ad_source=search\&ad_medium=search_result_all

Books, G. (2014, September 1). Metode Perencanaan \& Perancangan Arsitektur. Retrieved Januari 2020, from Griya Kreasi:

https://books.google.co.id/books?hl=en\&lr=\&id=T49kCAAAQBAJ\&oi=fnd\&pg=PA7\&dq $=$ metode+perancangan+arsitektur\&ots=KKJ_6rcfOK\&sig=dN_YG7HtwwJj_pfSPBx4XpoA $z 1 Y \&$ redir_esc $=\mathrm{y} \# \mathrm{v}=$ onepage $\& \mathrm{q}=$ metode\%20perancangan\%20arsitektur\& $\mathrm{f}=\mathrm{false}$

Wikipedia. (2020, Juli 3). Daftar Kecamatan dan Kelurahan di Kota Administrasi Jakarta Utara. Retrieved Januari 2020, from A. Wikimedia Project:

https://id.wikipedia.org/wiki/Daftar_kecamatan_dan_kelurahan_di_Kota_Administrasi_Ja ka rta_Utara

Wikipedia. (2020, Maret 22). Muara Angke. Retrieved Januari 2020, from A. Wikimedia Project: https://id.wikipedia.org/wiki/Muara_Angke. 